\title{
BAFF Expression is Increased in Patients with Lupus Nephritis and Associated with Antinucleosome Antibodies, C1 Inhibitor, A-1-Acid- Glycoprotein and Endothelial Activation Markers
}

\section{G. Ø. Eilertsen ${ }^{1 *}$, M. Van Ghelue ${ }^{2}$ and J.C. Nossent ${ }^{1}$}

${ }^{1}$ Bone and Joint research group, Department of Health Science, Medical School, University of Tromsø, Norway ${ }^{2}$ Medical Genetics Department, University Hospital North Norway, Troms $\varnothing$, Norway

\begin{abstract}
Objectives: B cell activating factor (BAFF) inhibitor therapy has recently been approved for non-renal Systemic Lupus Erythematosus (SLE). While BAFF plays a role in experimental lupus nephritis (LN), its role human LN is not well studied.

Methods: Case control study in 102 SLE patients, 30 with LN (+LN) and 72 without LN (-LN) and 31 healthy controls. We analysed BAFF mRNA expression in PBMCs (BAFF-RQ) and serum BAFF (s-BAFF) levels and investigated their relation with clinical, histological- and additional acute phase proteins.

Results: s-BAFF and BAFF-RQ were increased in $+L N$ patients compared to controls, but their expression did not correlate with ISN/RPS class, Activity- or Chronicity index on biopsy. s-BAFF correlated with levels of anti-nucleosome antibodies, $\mathrm{C} 1$ inhibitor and $\alpha-1$-acid-glycoprotein (AGP), while BAFF-RQ correlated inversely with Factor VIII.

Conclusions: s-BAFF and BAFF mRNA levels are increased in LN patients, but do not reflect histological disease severity. The association of increased BAFF expression with both pro- and anti-inflammatory markers and reduced endothelial activation suggest that BAFF inhibition in LN may have diverse effects.
\end{abstract}

Keywords: B-lymphocyte activating factor; Systemic Lupus Erythematosus; Lupus Nephritis;acute phase reactants; C1 inhibitor; a-1-acid-glycoprotein

Abbreviations: SLE: Systemic Lupus Erythematosus; LN: Lupus Nephritis; BAFF: B Cell Activating Factor, BAFF-RQ; BAFF gene expression; PBMCs: Peripheral Blood Mononuclear Cells, Ag: Antigen; vWF: Von Willebrand Factor; PTH: Para Thyreoid Hormone, AGP: a-1-Acid-Glyco Protein; LDH: Lactate De Hydrogenase

\section{Introduction}

Systemic Lupus Erythematosus (SLE) is the prototype of non-organ specific autoimmune diseases with renal disease as one of its most serious complications. Lupus nephritis (LN) occurs in $25 \%$ to $70 \%$ in patients with SLE at some point in the disease course [1,2]. A complex and incompletely understood interplay between renal infiltrating leukocytes, cytokines, autoantibodies and complement factors underlies the classical immune complex-mediated glomerulonephritis in LN [3]. Additionally, thrombotic and inflammatory vascular lesions can affect intrarenal or systemic haemodynamics and thus contribute to disease severity [4]. Autoantibodies produced by differentiated B cells are hallmarks of SLE, and B-cell activating factor (BAFF, TNFSF13 or BLyS) is a central cytokine in SLE pathogenesis. BAFF belongs to the tumor necrosis factor (TNF) superfamily [5] and is produced by a range of immune cells [6] with IL-2 and INF- $\gamma$ as known stimulants of BAFF $[7,8]$. Binding of BAFF to one of three receptors on mature $B$ cells (BAFF-R, TACI and BCMA), induces either Ig class switching, cell proliferation or increased survival of $B$ cells including autoreactive B cells [9]. Transgenic (Tg) mice that overexpress BAFF develop an autoimmune disorder, that resembles SLE including immunecomplex mediated glomerulonephritis [10-12]. In general, experimental studies suggest that overexpression of BAFF promotes LN, but evidence from human studies is lacking.

s-BAFF levels are frequently elevated in SLE patients and associated with disease activity, anti-dsDNA antibodies (Ab) levels and acute- phase reactants [13-15], while increased BAFF mRNA levels have been found to correlate with disease activity and anti-dsDNA Ab levels in some studies $[15,16]$. This suggests that BAFF may play a role in the development of LN through its effect on nephritogenic autoantibody production, although the exact mechanism remains unclear $[9,17]$.

Given the scarcity of human data on BAFF expression in LN, we investigated if any associations exist in vivo, between BAFF mRNA levels, s-BAFF levels and histological as well as biochemical findings in patients with LN.

\section{Materials and Methods}

\section{Study participants}

A total of 102 adult SLE patients (> 15 years) were recruited for this cross-sectional study and attended at an extended clinic visit, where biological materials were collected. They were predominantly of Caucasian descent $(98 \%)$, of female gender $(88 \%)$ with a median age of 49 years and disease duration of 10 years. All patients fulfilled the revised and/or updated American College of Rheumatology (ACR) criteria for the classification of SLE $[18,19]$. Healthy volunteers (all

*Corresponding author: Gro Østli Eilertsen, Department of Health Science, Medical School, University of Tromsø, Norway, Tel: +47 776 26125; Fax: +47 776 27258; E-mail: gro.eilertsen@uit.no

Received December 01, 2011; Accepted December 26, 2011; Published January 12,2012

Citation: Eilertsen G $\varnothing$, Ghelue MV, Nossent JC (2012) BAFF Expression is Increased in Patients with Lupus Nephritis and Associated with Antinucleosome Antibodies, C1 Inhibitor, A-1-Acid-Glycoprotein and Endothelial Activation Markers. $\mathrm{J}$ Data Mining in Genom Proteomics 3:113. doi:10.4172/2153-0602.1000113

Copyright: () 2012 Eilertsen G $\varnothing$, et al. This is an open-access article distributed under the terms of the Creative Commons Attribution License, which permits unrestricted use, distribution, and reproduction in any medium, provided the original author and source are credited. 
Citation: Eilertsen GØ, Ghelue MV, Nossent JC (2012) BAFF Expression is Increased in Patients with Lupus Nephritis and Associated with Antinucleosome Antibodies, C1 Inhibitor, A-1-Acid-Glycoprotein and Endothelial Activation Markers. J Data Mining in Genom Proteomics 3:113. doi:10.4172/2153-0602.1000113

Page 2 of 6

Caucasian, $71 \%$ females with age at 48 years) were used as controls for serological investigations and gene expression. The study protocol was approved by the local ethical committee, the national privacy agency and the Ministry of Health (ref. no 12420) and all participants gave written informed consent for the anonymous use of their data in compliance with the Helsinki Declaration.

\section{Clinical categorization of patients}

Lupus Nephritis (LN) was defined as sustained proteinuria ( $>0.5 \mathrm{~g} / 24$ hours) and/or the presence of $>5$ red blood cells and/ or $>5$ white blood cells and/or heme-granular or red blood cells casts (20). Renal tissue obtained through percutaneous biopsies was reevaluated independently by two pathologists for the following features: International Society of Nephrology/Renal Pathology Society (ISN/RPS) 2003 classification of LN [17,21] National Institutes of Health (NIH) Activity index (AI) and Chronicity index (CI) [22] and the presence of vasculitis/vascular thrombi. Histological scores represent the mean of the two observer scores and discrepancies in the classification were resolved by mutual discussion.

\section{Serology}

Serum BAFF levels were measured in duplex using a Quantikine Human BAFF/BLyS/TNFSF13B Immunoassay (R\&D Systems, Minneapolis, USA) and results were averaged. Anti-nuclear antibodies (ANA) positive sera were routinely tested by enzyme immunoassays EIiA (VarELISA Phadia, Freiburg, Germany) for the presence of IgG subclass antibodies $(\mathrm{Ab})$ against double stranded DNA (anti-dsDNA), Ro (anti-SSA), La (anti-SSB), Smith (anti-Sm) anti-U1 small nuclear ribonucleoparticle (anti-U1-snRNP) and cardiolipin (aCL-G and aCL-M; normal levels $<16 \mathrm{IU} / \mathrm{mL}$ ). Anti-nucleosome Ab was analysed by ELISA (Orgentec, Mainz, Germany). Lupus anticoagulant was tested in a phospholipid-dependent coagulation assay [23]. Routine laboratory investigations were performed in the accredited Department of Laboratory Medicine and Immunology at the University Hospital of Northern Norway.

\section{BAFF gene expression}

Primers and probes were designed using the BAFF encoding gene TNFSF13B (NC_000013.10) and B2M gene encoding $\beta 2$-microglobulin $(\beta 2 \mathrm{M})$ (NC_000015.9) as templates. Primers were designed using Enhanced Avian HS RT-PCR software (Sigma-Aldrich, Saint Quentin Fallavier, France) and probes were selected using Universal ProbeLibrary Human Gene Assay (Roche Diagnostics, Mannheim, Germany) [13].

Total RNA from frozen PBMCs was extracted using RNeasy Mini Kit (Qiagen, Hilden, Germany), following manufacturer's instructions. RNA was DNaseI treated (RNA-free), and stored at $-80^{\circ} \mathrm{C}$. Total RNA $(2 \mu \mathrm{g})$ was used to synthesize cDNA in a total volume of $20 \mu \mathrm{L}$ using SuperScript VILO cDNA Synthesis Kit (Invitrogen, CA, USA) with regard of investigation full-length BAFF mRNA, according to the protocol. The quality of cDNA was then confirmed by PCR using cDNA (0.5 $\mu \mathrm{l})$, adenine phosphoribosyltransferase gene (APRT) primers $(5 \mathrm{pM})$ and Jumpstart ready mix Red Taq DNA polymerase (Sigma-Aldrich, Saint Quentin Fallavier, France). Thermal conditions were denaturation at $94^{\circ} \mathrm{C}$ for $2 \mathrm{~min} ., 35$ cycles at $94^{\circ} \mathrm{C}$ for $10 \mathrm{sec} .65^{\circ} \mathrm{C}$ for $10 \mathrm{sec}$., and $72^{\circ} \mathrm{C}$ for $15 \mathrm{sec}$. and a final extension at $72^{\circ} \mathrm{C}$ for $5 \mathrm{~min}$. Agarose gel electrophoresis were run to ensure quality of cDNA, which was stored at $-20^{\circ} \mathrm{C}$.

Real-time PCR analysis was performed to determine the levels of BAFF mRNA in PBMCs using an ABI PRISM 7900HT, (version
2.3, Applied Biosystems, CA, USA). PCR reaction mixture contained $4 \mu \mathrm{l}$ cDNA, $10 \mu \mathrm{l}$ TaqMan MasterMix (TaqMan ${ }^{\circledR}$ Fast Universal PCR Master Mix (2x), No AmpErase ${ }^{\circledR}$ UNG, (Applied Biosystems), $5 \mu \mathrm{M}$ of each primer and probe in a final volume of $20 \mu$. Each analysis was performed with initial incubation at $95^{\circ} \mathrm{C}$ for $20 \mathrm{sec}$., followed by 40 cycles at $95^{\circ} \mathrm{C}$ for $1 \mathrm{sec}$. and $60^{\circ} \mathrm{C}$ for $20 \mathrm{sec}$. PCR reactions were done in triplicates. A range of primer concentrations was tested to ensure optimal amplification efficiency. Relative concentrations of cDNA present during the exponential phase of the reaction were determined by plotting fluorescence against cycle number on a logarithmic scale. A threshold for detection of fluorescence above background was determined. The BAFF transcript quantification was standardized using $\beta 2 \mathrm{M}$ as internal control. BAFF-RQ values are calculated as the ratios of BAFF mRNA to $\beta 2 \mathrm{M}$ mRNA using the following formula: $2 \exp$ $(\mathrm{Ct} \beta 2 \mathrm{M}-\mathrm{CtBAFF})$. Cut-off levels were determined by the geometric mean +2 S.D. for healthy controls $(n=31)$. The amplification was verified by melting curve analysis and crossing point. No amplification of non-specific products was observed.

\section{Statistics}

Due to relatively small numbers in the cohorts in addition to the fact that most data had a skewed distribution, nonparametric tests were used. Continuous data were analysed by Mann-Whitney U test, and categorical data by Poisson distribution contingency tables or Fishers' exact test in case of low numbers. Linear regression analyses were performed and linear correlations were analysed by Spearman rank correlation coefficients. Statistical analyses were performed with SPSS v19.0.

\section{Results}

\section{Study participants}

Among the 102 SLE patients, 30 (29\%) were presented with clinical evidence of LN during the disease course. There was no difference in gender ( $83 \%$ female vs. $88 \%, \mathrm{p}=0.5$ ), age at SLE diagnosis, $(27.5$ years vs. $37, \mathrm{p}=0.7$ ) (Table 1 ) or disease duration at study inclusion (12 years vs. $10, \mathrm{p}=0.5$ ) between $+\mathrm{LN}$ and $-\mathrm{LN}$ cohorts. Renal biopsy, performed on $17 / 30(57 \%)$ of the $+\mathrm{LN}$ patients after a median lag time of 2.5 years, showed an average AI of 7 and CI 2. The majority 12/17 (70\%) of the biopsies were classified as ISN / RPS class III or IV, with 2 (12\%) in class II, $2(12 \%)$ in class V and $1(6 \%)$ as class VI (Table 1$)$.

\section{Serum-BAFF and association with BAFF gene expression}

S-BAFF levels were higher in the $+\mathrm{LN}$ patients compared with controls (mean values; 2.09 vs $0.97 \mathrm{ng} / \mu \mathrm{l} ; \mathrm{p}<0.001$ ), (Figure 1 , Table 3). Similarly, BAFF mRNA levels were increased in +LN patients (RQ 1.88 , and 1.12, $\mathrm{p}<0.001$ ), (Figure 2). However, the differences between $+\mathrm{LN}$ and $-\mathrm{LN}$ patients were not statistically significant. In $+\mathrm{LN}$ patients there was no correlation between s-BAFF and full-length BAFF mRNA levels in PBMCs $\left(\mathrm{R}^{2} ; 0.29, \mathrm{p}=0.1\right)$ (Table 4).

\section{Renal biopsy findings and association with serum-BAFF and BAFF gene expression}

There was no significant difference in s-BAFF or BAFF-RQ levels between the different ISN/RPS classes (I-VI) (data not shown), while $\mathrm{s}$-BAFF or BAFF-RQ did not correlate with $\mathrm{AI}\left(\mathrm{R}^{2} ;-0.29, \mathrm{p}=0.3\right.$ vs. $\mathrm{R}^{2}$; $0.32, \mathrm{p}=0.2)$, nor $\mathrm{CI}\left(\mathrm{R}^{2} ; 0.28, \mathrm{p}=0.3\right.$ vs. $\left.\mathrm{R}^{2} ; 0.32, \mathrm{p}=0.2\right)$.

\section{Autoantibodies}

Compared with -LN patients, $+\mathrm{LN}$ patients more frequently had 
Citation: Eilertsen GØ, Ghelue MV, Nossent JC (2012) BAFF Expression is Increased in Patients with Lupus Nephritis and Associated with Antinucleosome Antibodies, C1 Inhibitor, A-1-Acid-Glycoprotein and Endothelial Activation Markers. J Data Mining in Genom Proteomics 3:113. doi:10.4172/2153-0602.1000113

Page 3 of 6

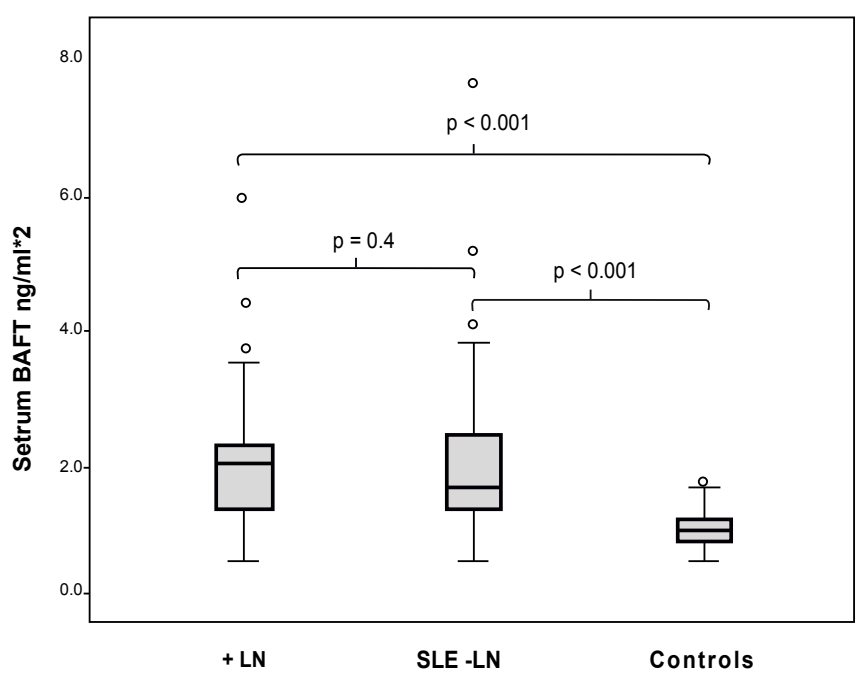

Figure 1: Serum BAFF levels in SLE patients with $(+L N)$ or without lupus nephritis (-LN) compared with healthy controls. The results are shown in box plots. The line inside the boxes indicates the medians; the outer borders of the boxes indicate the 25th and 75th percentiles; and the bars extending from the boxes indicate the 10th and 90th percentiles.

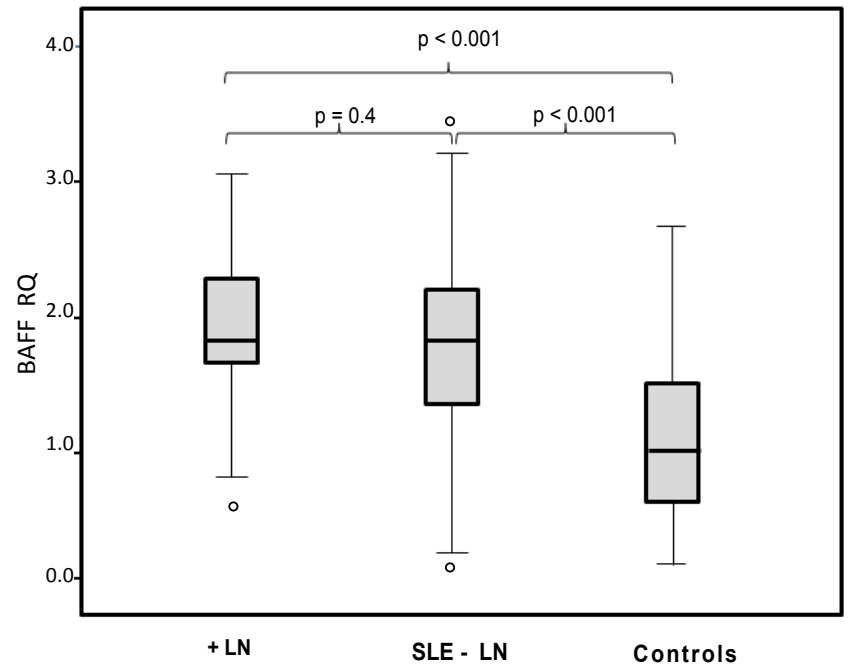

Figure 2: BAFF mRNA expression (BAFF-RQ) in SLE patients with (+LN) or without lupus nephritis (-LN) compared with healthy controls.

anti-nucleosome $\mathrm{Ab}(76 \%$ vs. 53\%, $\mathrm{p}=0.033)$ and anti-dsDNA $\mathrm{Ab}$ ( $43 \%$ vs. $25 \%, \mathrm{p}=0.06$ ), while other autoantibodies (anti-SM, anti-SSB, anti-SSB, anti-RNP, Coombs test and aPL) and hypocomplementemia were equally frequent present in both groups (Table 2). In the $+\mathrm{LN}$ cohort, the s-BAFF levels correlated with anti-nucleosome Ab levels $\left(\mathrm{R}^{2} ; 0.41, \mathrm{p}=0.01\right)$ (Table 4$)$, but not with anti-dsDNA, anti-RNP Ab, anti-cardiolipin (aCL) IgM, aCL IgG anti-C1q or complement levels. In the -LN cohort, s-BAFF levels correlated with anti-nucleosome $\mathrm{Ab}\left(\mathrm{R}^{2}\right.$; $0.27, p=0.02)$ and aCL IgG levels $\left(R^{2} ; 0.23, p=0.049\right)$ (data not shown).

\section{Immune cells and other laboratory findings}

Additional inflammatory biomarkers were measured in all freshly collected samples and the data were analyzed using a regression trend analysis between $+\mathrm{LN}$ patients, - LN patients and controls (Table 3). In $+\mathrm{LN}$ patients significant trends were seen with regard to low C3 ( 0.83 vs. 1.01 and $1.19 \mathrm{~g} / \mathrm{L}, \mathrm{p}<0.001$ ), increased coagulation Factor VIII (148 vs. 134 and $120 \%, \mathrm{p}=0.002$ ) and increased PTH (9.6 vs, 5.2 and $4.5 \mathrm{pmol} / \mathrm{L}, \mathrm{p}=0.026$ ) (Table 3). Additionally, significant trends were seen for lower NK cells, CD4 cells, C4, albumen and hemoglobin levels, with significant trends seen for increased $\mathrm{C} 1$ inhibitor, fibrinogen, von Willebrand Factor (vWF), vWF antigene, homocystein and LDH) (Table 3). No trend was seen for numbers of B- and CD8 cells, nor for levels of Ig, CRP, ferritin, cholesterol, triglycerides, apolipoproteine A1 and B, liver enzymes, FT4, TSH, vitamine B12, folat, HbA1c, IGF-1, IGFBP-3, alpha 1-antitrypsine, ceruloplasmine, $\alpha$-1-acid-glycoprotein (AGP) and alpha1-phoetoprotein (data not shown).

To examine the relation between these biomarkers and BAFF more closely, Spearman rank correlation analyses were performed. In +LN patients, s-BAFF concentrations had a strong and independent positive correlation with levels for $\mathrm{C} 1$ inhibitor $\left(\mathrm{R}^{2} ; 0.68, \mathrm{p}<0.001\right)$, AGP $\left(\mathrm{R}^{2}\right.$; $0.57, \mathrm{p}=0.002)$, haptoglobin $\left(\mathrm{R}^{2} ; 0.43, \mathrm{p}=0.024\right)$ and inversely with $\operatorname{IgA}$ $\left(\mathrm{R}^{2} ;-0.49, \mathrm{p}=0.009\right)$, albumin $\left(\mathrm{R}^{2} ;-0.48, \mathrm{p}=0.008\right)$, apolipoprotein $\mathrm{A} 1$ $\left(\mathrm{R}^{2} ;-0.62, \mathrm{p}=0.001\right)$ (Table 4). BAFF-RQ in $\mathrm{LN}+$ patients correlated inversely with factor VIII levels, but not with immune cells counts (B, NK, CD4 and CD8), complement levels (C3 and C4), IgG, IgM, CRP, ferritin, creatinine, fibrinogen, vWF, vWF Ag, transferrin, alphafoetoprotein, vitamin B12, IGF-1, HbA1c ionized calcium, alpha1antitrypsine, ceruloplasmine were not associated with s-BAFF or BAFF-RQ levels (data not shown).

\begin{tabular}{|l|l|l|}
\hline & $+\mathrm{LN} \mathrm{n=30} \mathrm{( \% )}$ & $-\mathrm{LN} \mathrm{n}=72(\%)$ \\
\hline Female no (\%) & $25(83)$ & $63(88)$ \\
\hline Age at SLE diagnosis & 27.5 & 37 \\
\hline Disease duration at study & 12 & 10 \\
\hline Age at LN & 27.5 & \\
\hline Renal biopsy performed & $17(59)$ & \\
\hline Years between LN and biopsy & 2 & \\
\hline Biopsy findings: & & \\
\hline Activity Index & 7 & \\
\hline Chronicity Index & 2 & \\
\hline LN Class II & 2 & \\
\hline LN Class III & 5 & \\
\hline LN Class IV & 7 & \\
\hline LN Class V & 2 & \\
\hline LN Class VI & 1 & \\
\hline
\end{tabular}

LN; Classification of lupus nephritis. International Society of Nephrology/Rena Pathology Society (ISN/RPS) $2003(17 ; 21)$ Numbers; median values or patients

Table 1: Descriptors of study cohort of SLE patients with $(+L N)$ or without lupus nephritis.

\begin{tabular}{|l|l|l|l|}
\hline & $\mathbf{+ L N} \mathbf{n = 3 0 ( \% )}$ & -LN $\mathbf{n = 7 2 ( \% )}$ & p-value \\
\hline Anti-dsDNA Ab & $13(43)$ & $18(25)$ & 0.06 \\
\hline Anti-Nucleosome Ab & $22(76)$ & $38(53)$ & 0.033 \\
\hline Anti-SM Ab & $2(7)$ & $3(4)$ & 0.6 \\
\hline Anti-SSA Ab & $9(30)$ & $27(38)$ & 0.5 \\
\hline Anti-SSB Ab & $2(7)$ & $4(6)$ & 1.0 \\
\hline Anti-RNP Ab & $3(10)$ & $15(21)$ & 0.3 \\
\hline Coombs test & $6(20)$ & $10(14)$ & 0.5 \\
\hline aPL Ab & $6(20)$ & $11(15)$ & 0.6 \\
\hline Low complement & $10(36)$ & $17(23)$ & 0.2 \\
\hline
\end{tabular}

Table 2: Prevalence of autoantibodies $(A b)$ and hypocomplementemia in SLE patients with $(+L N)$ and without lupus nephritis (-LN). 
Citation: Eilertsen GØ, Ghelue MV, Nossent JC (2012) BAFF Expression is Increased in Patients with Lupus Nephritis and Associated with Antinucleosome Antibodies, C1 Inhibitor, A-1-Acid-Glycoprotein and Endothelial Activation Markers. J Data Mining in Genom Proteomics 3:113. doi:10.4172/2153-0602.1000113

Page 4 of 6

\begin{tabular}{|c|c|c|c|c|c|}
\hline & $+\mathrm{LN} n=30$ & $-L N n=72$ & Control $n=31$ & Univariate $\beta$ & p-value \\
\hline 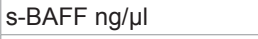 & $2.09 \pm 1.14$ & $1.91 \pm 1.09$ & $0.97 \pm 0.27$ & 0.57 & $<0.001$ \\
\hline BAFF-RQ & $1.88 \pm 0.60$ & $1.75 \pm 0.64$ & $1.12 \pm 0.64$ & 0.38 & $<0.001$ \\
\hline NK cells, $10^{9} / \mathrm{L}$ & $0.13 \pm 0.10$ & $0.13 \pm 0.08$ & $0.26 \pm 0.11$ & -0.05 & 0.002 \\
\hline CD4 cells, $10^{9} / \mathrm{L}$ & $0.53 \pm 0.30$ & $0.64 \pm 0.33$ & $1.0 \pm 0.33$ & -0.20 & $<0.001$ \\
\hline C3, g/L & $0.83 \pm 0.31$ & $1.01 \pm 0.24$ & $1.19 \pm 0.27$ & -0.18 & $<0.001$ \\
\hline C4, g/L & $0.13 \pm 0.06$ & $0.17 \pm 0.07$ & $0.22 \pm 0.05$ & -0.04 & $<0.001$ \\
\hline $\mathrm{Hb}, \mathrm{g} / \mathrm{L}$ & $12.5 \pm 2.0$ & $13.2 \pm 1.5$ & $13.5 \pm 1.7$ & -0.48 & 0.021 \\
\hline Albumen, g/L & $40.3 \pm 4.8$ & $43.5 \pm 2.9$ & $44.8 \pm 2.5$ & -2.37 & $<0.001$ \\
\hline Fibrinogen, g/L & $3.9 \pm 0.7$ & $3.4 \pm 0.8$ & $3.4 \pm 0.7$ & 0.25 & 0.028 \\
\hline VWF (\%) & $121 \pm 28$ & $109 \pm 32$ & $87 \pm 37$ & 16.0 & 0.001 \\
\hline Faktor VIII (\%) & $148 \pm 23$ & $134 \pm 29$ & $120 \pm 36$ & 14.2 & 0.002 \\
\hline VWF antigen (\%) & $143 \pm 31$ & $136 \pm 34$ & $106 \pm 36$ & 16.8 & 0.001 \\
\hline $\mathrm{LDH}, \mathrm{U} / \mathrm{L}$ & $206 \pm 105$ & $177 \pm 57$ & $155 \pm 17$ & 25.9 & 0.015 \\
\hline Homocysteine, $\mu \mathrm{mol} / \mathrm{L}$ & $12.9 \pm 7.9$ & $10.4 \pm 4.3$ & $8.8 \pm 2.6$ & 2.16 & 0.011 \\
\hline PTH, pmol/L & $9.6 \pm 16.7$ & $5.2 \pm 2.1$ & $4.5 \pm 1.7$ & 2.78 & 0.026 \\
\hline Ionized $\mathrm{Ca}, \mathrm{mmol} / \mathrm{L}$ & $1.22 \pm 0.04$ & $1.28 \pm 0.59$ & $1.23 \pm 0.03$ & -0.02 & 0.8 \\
\hline Haptoglobin, g/L & $1.51 \pm 0.63$ & $1.34 \pm 0.67$ & $1.43 \pm 0.58$ & 0.06 & 0.5 \\
\hline AGP, g/L & $1.05 \pm 0.36$ & $0.96 \pm 0.33$ & $0.87 \pm 0.19$ & 0.09 & 0.1 \\
\hline Apolipoprotein A, g/L & $1.61 \pm 0.34$ & $1.52 \pm 0.38$ & $1.47 \pm 0.38$ & 0.07 & 0.2 \\
\hline C1 inhibitor, g/L & $0.34 \pm 0.06$ & $0.33 \pm 0.07$ & $0.30 \pm 0.04$ & 0.02 & 0.047 \\
\hline
\end{tabular}

BAFF-RQ; BAFF gene expression; vWF; vonWillebrand factor, PTH; Parathyreoid hormone, AGP; $\alpha$-1-acid-glycoprotein, LDH; Lactate dehydrogenase

Table 3: Laboratory findings in lupus nephritis patients $(+L N)$, SLE patients without $L N(-L N)$ and controls. Figures indicate mean \pm SD while $\beta$ and $p-v a l u e s$ reflect linear trend analyses.

\begin{tabular}{|c|c|c|c|c|c|c|c|c|c|c|c|c|}
\hline & s-BAFF & BAFF-RQ & $\alpha-D N A$ & a-Nucl. & $a-C 1 q$ & $\mathrm{aCL}$ & C3 & $\mathrm{C} 4$ & $\lg A$ & Albumin & APG & ApoA1 \\
\hline BAFF-RQ & - & & & & & & & & & & & \\
\hline$\alpha-D N A$ & - & - & & & & & & & & & & \\
\hline a-Nucl. &, $41^{*}$ & - &, $55^{\star *}$ & & & & & & & & & \\
\hline$\alpha-C 1 q$ & - & - &, $75^{\star *}$ &, $58^{\star *}$ & & & & & & & & \\
\hline $\mathrm{aCL}$ & - & - &, $55^{\star *}$ &, $57^{* *}$ & ,43* & & ,39* & & & & & \\
\hline C4 & - & - &,$- 48^{\star *}$ &,$- 55^{\star *}$ & - &,$- 37^{*}$ &, $69^{* *}$ & & & & & \\
\hline
\end{tabular}

\begin{tabular}{lllllllll}
\hline $\lg \mathrm{A}$ &,$- 49^{* *}$ & - & - & - & - & - & - & - \\
\hline Albumin & & & & & & & \\
\hline
\end{tabular}

\begin{tabular}{|c|c|c|c|c|c|c|c|c|c|c|}
\hline Factor VIII & - &,$- 44^{*}$ & - & - & - & - & - & - & - & - \\
\hline APG &, $57^{* *}$ & - & - &, $44^{*}$ & - & - & - & - &, $43^{*}$ & - \\
\hline
\end{tabular}

\begin{tabular}{|c|c|c|c|c|c|c|c|c|c|c|c|}
\hline Haptoglobin &, $43^{*}$ & - & - & - & - & - &,$- 54^{* *}$ & - & - & - &, $48^{*}$ \\
\hline C1 inhibitor &, $68^{* *}$ & - & - & - & - & - & - & - & - &, $40^{*}$ & - \\
\hline
\end{tabular}

\begin{tabular}{|c|c|c|c|c|c|c|c|c|c|c|c|c|}
\hline C1 inhibitor &, $68^{* *}$ & - & - & - & - & - & - & - & - & ,40* & - & \\
\hline ApoA1 &,$- 62^{* *}$ & - & - &,$- 52^{* *}$ & - & - & - & - &,$- 57^{* *}$ & - & - & \\
\hline ApoB & - &,$- 39^{*}$ & - & - & - & - & - & - & - & - & - &, $41^{*}$ \\
\hline
\end{tabular}

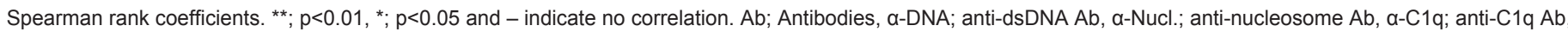
aCL; anti-cardiolipin IgG Ab, AGP; $\alpha$-1-acid-glycoprotein, ApoA1; Apolipoprotein A1, ApoB; Apolipoprotein B

Table 4: Correlations between s-BAFF levels, BAFF gene expression (BAFF-RQ) and circulating factors in patients with lupus nephritis ( $n=30$ ).

In contrast, s-BAFF levels in -LN patients were correlated with CRP $\left(\mathrm{R}^{2} ; 0.36, \mathrm{p}=0.002\right)$, fibrinogen $\left(\mathrm{R}^{2} ; 0.25, \mathrm{p}=0.049\right)$ and $\operatorname{IgM}\left(\mathrm{R}^{2}\right.$; $-0.26, \mathrm{p}=0.039)$. Similar as the $+\mathrm{LN}$ cohort, in the $-\mathrm{LN}$ group s-BAFF levels correlated with AGP $\left(\mathrm{R}^{2} ; 0.30, \mathrm{p}=0.014\right)$, although not as strong.
In the -LN cohort, BAFF-RQ correlated only with markers not found in the $+\mathrm{LN}$ group (inverse correlation with $\mathrm{CD} 4$ cell counts $\left(\mathrm{R}^{2} ;-0.28\right.$, $\mathrm{p}=0.024)$ and $\operatorname{IgG}\left(\mathrm{R}^{2} ;-0.30, \mathrm{p}=0.018\right)$. 
Citation: Eilertsen GØ, Ghelue MV, Nossent JC (2012) BAFF Expression is Increased in Patients with Lupus Nephritis and Associated with Antinucleosome Antibodies, C1 Inhibitor, A-1-Acid-Glycoprotein and Endothelial Activation Markers. J Data Mining in Genom Proteomics 3:113. doi:10.4172/2153-0602.1000113

Page 5 of 6

\section{Discussion}

This cross sectional study investigated several aspects of BAFF to increase our understanding of the contribution of BAFF in human $\mathrm{LN}$. We show that both BAFF gene expression and s-BAFF levels were increased in LN patients, but there is no linear correlation between them. Also, while s-BAFF was associated to anti-nucleosome Ab levels neither s-BAFF levels nor BAFF gene expression was associated with the histological severity of LN; however s-BAFF was strongly associated with levels of the anti-inflammatory $\mathrm{C} 1$ inhibitor protein.

A recent study from Switzerland showed increased mRNA expression of BAFF in glomeruli and tubulointerstitial tissue of patients with proliferative LN as compared with living donors [24]. BAFF gene expression in the PBMCs of LN patients in this study was unrelated to the histological findings, suggesting that BAFF gene expression occurring in the inflamed renal tissues may be of greater importance. Our study design did not allow gene expression studies in tissues or other cell types, which would have been of interest to determine whether the source of renal BAFF expression is intrinsic renal cells or infiltrating leukocytes. The fact that BAFF mRNA expression in PBMCs did not correlate with s-BAFF suggest a limited role of PBMCs in this process [13]. Furthermore, no correlation between $B A F F$ gene expression and the nephritogenic antibodies against nucleosome and ds-DNA were observed in LN patients, which is in accordance with the lack of association between $B A F F$ expression and renal disease observed in lupus prone mice, that strongly express anti-nucleosome and anti-dsDNA Ab [25].This raises questions, whether there is a direct link between $B A F F$ expression by PBMCs and pathogenic autoantibody production.

In line with other studies, anti-nucleosome $\mathrm{Ab}$ and anti-dsDNA Ab were more prevalent in LN patients compared with SLE patients without renal involvement $[4,26]$. Even though we observed a strong correlation between autoantibodies that are typically considered pathogenic in LN (Table 4), anti-nucleosome $\mathrm{Ab}$ was the only which correlated with s-BAFF. This correlation has not yet been described in the literature, but would suggest a role for BAFF in anti-nucleosome production in LN. Immune deposits which consist of oligo-nucleosomes, are located in the basement membrane in the renal glomeruli [27] in LN and are considered the result of ineffective clearance of apoptotic material $[28,29]$; this may then trigger antigen presenting cells to produce BAFF, that subsequently is involved in the production of anti-nucleosome $\mathrm{Ab}$.

We observed an inverse correlation between BAFF gene expression and, coagulation factor VIII and apolipoprotein B in LN patients. These finding have not been described in the literature before, but the increased factor VIII and vWF indicate a state of endothelial activation in LN patients as plasma vWF binds to collagen in the subendothelial connective tissue. Collagen binding appears to induce a conformational change within the factor VIII-binding motif of vWF that lowers the affinity for factor VIII. Consequently, released factor VIII may locally support fibrin clot formation, and thus contribute to renal thrombotic vascular lesions [30]. Finally, we found increased PTH levels in LN patients while ionized calcium levels were found to be normal, which likely indicates a predisposition to osteopenia in patients with LN.

Several other proteins were studied for their association with BAFF in LN. s-BAFF was strongly correlated with AGP, which is an acute phase reactant that act as a carrier of basic and neutrally charged lipophilic compounds and has been suggested as a useful biomarker for LN [31]. In active LN , elevated AGP is observed both in plasma and urine, where urinary levels of AGP is increased 3 months prior to the clinical diagnosis of worsening LN activity [32]. High levels of s-BAFF were also associated with low levels of apolipoprotein A1, which is a major component of the high-density lipoprotein complex (HDL). Lipid abnormalities like reduced HDL levels and apolipoprotein A1 are likely to be contributing causes to cardiovascular disease risk which is increased in patients with SLE [37]. HDL is an atheroprotective lipoprotein that contributes to reverse cholesterol transport from the atherosclerotic vessels back to the liver. While HDL-associated apolipoprotein A1 is a specific inhibitor of cytokine production in monocyte-macrophages upon contact with stimulated $\mathrm{T}$ cells, this complex might have important anti-inflammatory properties by inhibiting endothelial cells [38]. In this way, BAFF may protect against endothelial activation and vascular damage.

$\mathrm{C} 1$ inhibitor can prevent activation of the complement system by blocking the classical and lectin activation pathways at the protease step [33]. C1 inhibitor behaves as an acute-phase reactant, and has additional anti-inflammatory functions such as reduced rolling and transmigration of leukocytes across the endothelium and interacts with extracellular matrix components to concentrate $\mathrm{C} 1$ inhibitor at sites of inflammation [33]. The fact that s-BAFF was strongly associated with $\mathrm{C} 1$-inhibitor, but only in $\mathrm{LN}+$ patients could indicate that BAFF expression coincides with the acute phase response. The observed corresponding associations of BAFF with AGP and fibrinogen levels would support this.

The limitations of this study need mentioning. SLE is characterised by intermittent disease activity and laboratory findings. The data from this cross-sectional analysis cannot allow any conclusions about BAFF expression levels over time, despite the fact that variation in s-BAFF levels appear to be limited [15]. The study design also limits the strength of the correlation between serological and histological findings. Finally, the small number of LN patients increases the possibility of type II error, and similar studies that include more patients are required before a final conclusion can be made.

In summary, our results show that both s-BAFF levels and PBMCs BAFF gene expression are increased in patients with LN. While s-BAFF levels correlated with nephritogenic autoantibodies, they were also correlated with the anti-inflammatory markers $\mathrm{C} 1$ inhibitor and AGP, as well as reduced endothelial activation. Based on these findings, targeted treatments to inhibit BAFF might be relevant in patients with LN, but also has the potential for unwanted effects on BAFF related anti-inflammatory mechanisms.

\section{Acknowledgement}

We thank Kirsten Nilsen for excellent technical help and Andrea BeckerMerok, for help in ascertaining and examining the patients.

\section{Funding Statement}

This work was supported by grants of Norsk Revmatikerforbund, Oslo Sanitetsforening and the Scandinavian Rheumatology Research Foundation.

\section{References}

1. Bomback AS, Appel GB (2010) Updates on the treatment of lupus nephritis. Am Soc Nephrol 21: 2028- 2035.

2. O'Neill S, Cervera R (2010) Systemic lupus erythematosus. Best Pract Res Clin Rheumatol 24: 841-855.

3. Hahn BH (1998) Antibodies to DNA. N Engl J Med 338: 1359- 1368.

4. Seshan SV, Jennette JC (2009) Renal disease in systemic lupus erythematosus with emphasis on classification of lupus glomerulonephritis: advances and implications. Arch Pathol Lab Med 133: 233- 248. 
Citation: Eilertsen GØ, Ghelue MV, Nossent JC (2012) BAFF Expression is Increased in Patients with Lupus Nephritis and Associated with Antinucleosome Antibodies, C1 Inhibitor, A-1-Acid-Glycoprotein and Endothelial Activation Markers. J Data Mining in Genom Proteomics 3:113. doi:10.4172/2153-0602.1000113

Page 6 of 6

5. Ryan MC, Grewal IS (2009) Targeting of BAFF and APRIL for Autoimmunity and Oncology. Adv Exp Med Biol 647: 52- 63.

6. Mackay F, Silveira PA, Brink R (2007) B cells and the BAFF/APRIL axis: fastforward on autoimmunity and signaling. Curr Opin Immunol 19: 327- 336.

7. Harigai M, Kawamoto M, Hara M, Kubota T, Kamatani N, et al. (2008) Excessive production of IFN-gamma in patients with systemic lupus erythematosus and its contribution to induction of B lymphocyte stimulator/B cell-activating factor/TNF ligand superfamily-13B. J Immunol 181: 2211- 2219.

8. Suzuki K, Setoyama Y, Yoshimoto K, Tsuzaka K, Abe T, et al. (2008) Effect of interleukin-2 on synthesis of $B$ cell activating factor belonging to the tumor necrosis factor family (BAFF) in human peripheral blood mononuclear cells. Cytokine 44: 44- 48.

9. Mackay F, Schneider P (2009) Cracking the BAFF code. Nat Rev Immunol 9: 491- 502.

10. Fletcher CA, Sutherland AP, Groom JR, Batten ML, Ng LG, et al. (2006) Development of nephritis but not sialadenitis in autoimmune-prone BAFF transgenic mice lacking marginal zone B cells. Eur J Immunol 36: 2504- 2514.

11. Fletcher CA, Groom JR, Woehl B, Leung H, Mackay C, et al. (2011) Development of autoimmune nephritis in genetically asplenic and splenectomized BAFF transgenic mice. J Autoimmun 36: 125- 134.

12. Stohl W, Xu D, Kim KS, Koss MN, Jorgensen TN, Deocharan B, et al. (2005) BAFF overexpression and accelerated glomerular disease in mice with an incomplete genetic predisposition to systemic lupus erythematosus. Arthritis Rheum 52: 2080- 2091.

13. Eilertsen GO, Van GM, Strand H, Nossent JC (2011) Increased levels of BAFF in patients with systemic lupus erythematosus are associated with acute-phase reactants, independent of BAFF genetics: a case-control study. Rheumatology. Rheumatology 50: 2197- 2205

14. Petri M, StohI W, Chatham W, McCune WJ, Chevrier M, et al. (2008) Association of plasma B lymphocyte stimulator levels and disease activity in systemic lupus erythematosus. Arthritis Rheum 58: 2453-2459.

15. Stohl W, Metyas S, Tan SM, Cheema GS, Oamar B, et al. (2003) B lymphocyte stimulator overexpression in patients with systemic lupus erythematosus: longitudinal observations. Arthritis Rheum 48: 3475- 3486.

16. Ju S, Zhang D, Wang $\mathrm{Y}$, Ni H, Kong X, et al. (2006) Correlation of the expression levels of BLyS and its receptors mRNA in patients with systemic lupus erythematosus. Clin Biochem 39: 1131-1137.

17. Weening JJ, D'Agati VD, Schwartz MM, Seshan SV, Alpers CE, et al. (2004) The classification of glomerulonephritis in systemic lupus erythematosus revisited. J Am Soc Nephrol 15: 241- 250.

18. Hochberg MC (1997) Updating the American Collage of Rheumatology revised criteria for the classification of systemic lupus erythematosus. Arthritis Rheum 40:1725

19. Tan EM, Cohen AS, Fries JF, Masi AT, McShane DJ, et al. (1982) The 1982 revised criteria for the classification of systemic lupus erythematosus. Arthritis Rheum 25: 1271- 1277.

20. Bombardier C, Gladman DD, Urowitz MB, Caron D, Chang CH (1992) Derivation of the SLEDAI A disease activity index for lupus patients The Committee on Prognosis Studies in SLE. Arthritis Rheum 35: 630- 640.

21. Austin HA, Boumpas DT, Vaughan EM, Balow JE (1994) Predicting rena outcomes in severe lupus nephritis: contributions of clinical and histologic data. Kidney Int 45: 544- 550.

22. Austin HA, Muenz LR, Joyce KM, Antonovych TA, Kullick ME, et al. (1983) Prognostic factors in lupus nephritis Contribution of renal histologic data. Am J Med 75: 382-391.

23. Brandt JT, Triplett DA, Alving B, Scharrer I (1995) Criteria for the diagnosis of lupus anticoagulants: an update On behalf of the Subcommittee on Lupus Anticoagulant/Antiphospholipid Antibody of the Scientific and Standardisation Committee of the ISTH. Thromb Haemost 74: 1185- 1190.

24. Neusser MA, Lindenmeyer MT, Edenhofer I, Gaiser S, Kretzler M, et al. (2011) Intrarenal production of B-cell survival factors in human lupus nephritis. Mod Pathol 24: 98- 107.

25. Jacob CO, Pricop L, Putterman C, Koss MN, Liu Y, et al. (2006) Paucity of clinical disease despite serological autoimmunity and kidney pathology in lupus-prone New Zealand mixed 2328 mice deficient in BAFF. J Immunol 177 2671- 2680.

26. van Bruggen MC, Kramers C, Walgreen B, Elema JD, Kallenberg CG, et al (1997) Nucleosomes and histones are present in glomerular deposits in human lupus nephritis. Nephrol Dial Transplant 12: 57- 66.

27. Kalaaji M, Mortensen E, Jorgensen L, Olsen R, Rekvig OP (2006) Nephritogenic lupus antibodies recognize glomerular basement membrane-associated chromatin fragments released from apoptotic intraglomerular cells. Am J Pathol 168: $1779-1792$

28. Kuenkele S, Beyer TD, Voll RE, Kalden JR, Herrmann M (2003) Impaired clearance of apoptotic cells in systemic lupus erythematosus: challenge of $T$ and B cell tolerance. Curr Rheumatol Rep 5: 175- 177

29. Zykova SN, Seredkina N, Benjaminsen J, Rekvig OP (2008) Reduced fragmentation of apoptotic chromatin is associated with nephritis in lupus-prone $(\mathrm{NZB} \times \mathrm{NZW}) \mathrm{F}(1)$ mice. Arthritis Rheum 58: 813- 825.

30. Spiel AO, Gilbert JC, Jilma B von (2008) Willebrand factor in cardiovascular disease: focus on acute coronary syndromes. Circulation 117: 1449-1459.

31. Das L, Brunner HI (2009) Biomarkers for renal disease in childhood. Curr Rheumatol Rep 11: 218- 225.

32. Suzuki M, Wiers K, Brooks EB, Greis KD, Haines K, et al. (2009) Initial validation of a novel protein biomarker panel for active pediatric lupus nephritis. Pediatr Res 65: 530- 536

33. Davis AE, Lu F, Mejia $P$ (2010) C1 inhibitor, a multi-functional serine protease inhibitor. Thromb Haemost 104: 886- 893. 